\section{Multidisciplinary \\ SCIENTIFIC JOURNAL OF MARITIME RESEARCH}

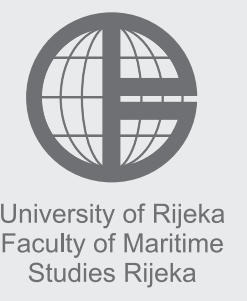

Multidisciplinarni

znanstveni časopis

POMORSTVO

https://doi.org/10.31217/p.32.2.1

\title{
Mathematical Modelling of Diesel Engine Operational Performance Parameters in Transient Modes
}

\author{
Paulius Rapalis ${ }^{1}$, Sergejus Lebedevas ${ }^{2}$, Rima Mickevičienè ${ }^{2}$ \\ ${ }^{1}$ Marine Research Institute, Waterborne Transport and Air Pollution Laboratory, Klaipeda University, Klaipeda, Lithuania, Paulius.Rapalis@ku.lt \\ ${ }^{2}$ Faculty of Marine Technologies and Natural Sciences, Department of Marine Engineering, Klaipeda University, Bijūnų str. 17 LT-91225 Klaipeda, \\ Lithuania, e-mail: Sergejus.Lebedevas@ku.lt; rima.mickeviciene@ku.lt
}

\section{ABSTRACT}

This study presents innovative methods for solving practical challenges that occur during the operation of heavy diesel engines (DEs). The novelty of the method arises from the combined use of an artificial neural network, a single-zone DE combustion mathematical model, and data from real operation conditions. Using the proposed method, DE transient mode energy efficiency has been analysed, and the primary influencing factors have been identified: $\mathrm{q}_{\text {cycl }}$ and $\mathrm{dq}_{\text {cycl }} / \mathrm{dt}$. The adequacy of the method has been tested for CAT3512B-HD series engines installed on freight locomotives. The difference between the model results and experimental data has been 3-4\%. CAT3512B-HD series DE transient operation studies have shown that at the low-load range of $\mathrm{q}_{\text {cycl }}$ (up to $36 \%$ of nominal), the fuel consumption during transient operation increases by $10 \%$ compared to steady state operation. Transient operation efficiency is not influenced by the operation rate $\left(\mathrm{dq}_{\mathrm{cyc}} / \mathrm{dt}\right)$ in the analysed -0.016 to $0.016 \mathrm{~g} / \mathrm{s}$ range. Near the nominal power $\left(\mathrm{q}_{\text {cycl }}\right.$ increases up to $0.5 \mathrm{~g} /$ cycle $)$, it is necessary to limit the $\mathrm{dq}_{\mathrm{cyc}} / \mathrm{dt}$ range to $0.006 \mathrm{~g} / \mathrm{s}$ to avoid overexploitation of the fuel by more than $100 \%$. The proposed method has been recommended for practical use in optimizing vehicle operation load cycle structure by adapting the engine control to the concrete operation conditions, as well as for overall efficiency improvement.
\end{abstract}

\section{ARTICLE INFO}

Original scientific paper

Received 30 May 2018

Accepted 9 November 2018

\section{Key words:}

Transient modes

Single zone mathematical models

Artificial neural networks

Diesel engine energy parameters

Dynamic factors

\section{Introduction}

Mathematical modelling of diesel engine (DE) performance, including energy efficiency parameters, enables significant savings in the cost and time required for experimental preparation. Mathematical modelling methods are particularly effective for real operation conditions in which implementation of experiments is difficult or not possible. This is primarily a result of the DE transient modes, which constitute a major factor in the operational lifetime of a vehicle (Rakopoulos, Giakoumis 2009). Simulation of DE steady state operational modes with a wide range of models is well adapted and has been widely applied in DE research (Merker et al. 2006; Rakopoulos, Giakoumis 2009; Rapalis et al. 2013; Kumar et al. 2013). However, modelling DE transient operational modes is complicated owing to multiple changes in the parameters of the operational processes occurring in the DE cylinders and systems. In many cases, these parameters still have no accurate analytical description and are difficult to validate properly with experiments.

However, current stringent environmental regulations (Zbarcea et al. 2016; Brand 2016) along with international agreements and conventions (White paper 2011) have caused an increased interest in DE transient modes. The determination, evaluation, and optimisation of energy performance under DE operational conditions to improve energy efficiency are crucial for addressing various environmental issues (Brand 2016).

The modelling of a DE operation in the transient loading mode has been studied widely by C. D. Rakopoulos. A mathematical model has been proposed for a single DE cylinder without a turbocharger, taking into account engine friction, inertia, and dynamic parameters of the highpressure fuel pump and regulator (Rakopoulos, Giakoumis 1998; 2006). This model has then been improved by adapting it for a 6-cylinder DE with a turbocharger. The resulting model has been exceptional as it was able to 
simulate the performance of a multi-cylinder engine (Rakopoulos, Giakoumis 2004; Rakopoulos et al. 1998). This model has since been subject to further improvement (Rakopoulos, Giakoumis 2006; 2006). An automotive DE mathematical modelling has been carried out by G. Zhang and others (Zhang et al. 1997), who has improved the mathematical model created by D. N. Assanis (Assanis 1985 ) by supplementing it with an evaluation of the influence of engine dynamics (Zhang et al. 1997). Overall, most attention in the literature has been paid to filling and emptying based and semi-linear models owing to their high calculation speeds (Rakopoulos, Giakoumis 2006; Winkler 2008; Yelvington 2013).

Recently, specialised digital modelling tools for internal combustion engines have been used for research on transient modes, including GT-power, AVL BOOST, AVL FIRE, Ricardo, and OpenWam. (Yelvington 2013; Willermark, Smith; Winkler 2008; Florián et al. 2006). Reviewing the DE mathematical modelling research shows that the Vibe and Woschni/Anisits heat release models have been used effectively for these simulations (Chakrabarti, et al. 2012; Rakopoulos, Giakoumis 2006). This is likely owing to the simplicity of usage of these models and the relatively small amount of required initial data. In contrast, using the multizone AVL, MMC, or Hiroyasu models requires detailed fuel supply system data that can be determined only during the engine design phase by dismantling the DE and conducting research in specialized labs (Rapalis et al. 2013). An even more complex application of these models would be required for research on transient loading modes.

With more available software and improved efficiency, the scope of these studies and use of these tools has increased (Winkler 2008; Smith; Bermúdez et al. 2011). Yelvington used the "Ricardo" digital modelling software to investigate DE operation in transient modes for creating a hybrid-electric turbocompressor. Yelvington has also noted that mathematical modelling software packages can be useful tools in the engine design process. (Yelvington 2013; Bermúdez et al. 2011). Nüescha et al.have also used digital modelling tools with the aim to reduce emissions from hybrid (diesel-electric) vehicles during transient loading modes (Nüescha et al. 2014).

N. Winkler has investigated the influence of turbocharging on parameters of heavy vehicle DEs using GT-Power mathematical modelling tools. During that research, it has been noted that forecasting turbocompressor operation in transient modes is very difficult. Winkler has also noted that the system has been most beneficial during the initial phase of turbocompressor design when high accuracy is not required (Winkler 2008). A research on non-road transport DE transient modes, using mathematical modelling tools, has been carried out by M. Kotus, M. Pexa, and K. Kubin. They have conducted experimental tests using a non-road transport transient testing cycle, which has then been used as the basis for the development of an interpolative mathematical model of harmful emissions. It has been concluded that the model has good reproducibility, but its interpolative character may result in errors in certain transient modes (Kotus et al. 2005). The analysis of previous transient DE mathematical modelling studies has revealed that these models are often purposefully simplified and applied only to research on a particular DE component (Bermúdez et al. 2011). These models may be used in design when detailed design data are available (Imamori 2011), but even in that case, long calculation times are inevitable (Imamori 2011).

Modern engine control technologies including multistage injection, variable geometry turbochargers, and variable valve timing improve DE performance. However, these systems increase the number of degrees of freedom in the models, and their control and definition of synergy effects become increasingly difficult to simulate with physical or phenomenological models. Moreover, investigation of transient loads complicates the research further, and not only the accuracy of the results, but also the increasing scope of the calculations becomes problematic. In this context, there is a tendency to use approximations of the experimental data with artificial neural networks (ANN) (Brzozowska 2007; Ismaila et al. 2012; Taghavifar et al. 2014; Roy et al. 2014; Manieniyana et al. 2016, Tanga et al. 2017, Kshirsagar, Anand 2017).

Artificial neural networks are one of the most successful and widely applied technologies that have appeared in the last two decades (Kriesel 2005; Graupe 2007). Neural network technologies have been recently introduced for DE research (Wu et al., 2004; Florián et al. 2006; Brzozowska 2007; Ismaila et al. 2012; Nikzadfar K. 2014; Roy et al. 2014; Taghavifar et al. 2014; Manieniyana et al. 2016; Tanga et al. 2017, Kshirsagar, Anand 2017; Gürgen et al. 2018; Kurtgoz et al. 2018).

The application of neural network approximation mechanisms and the usage of nonlinear functions in neural networks can avoid large data tables and complex calculations of physicochemical processes. In addition, their speed and accuracy can surpass those of phenomenological models for transient load researches. These black box models can define links among several single (one input - one output) and multiple (many inputs - many outputs) parameters (Kriesel 2005; Graupe 2007; Deng et al. 2011). This is directly applicable to transient load modelling, in which the common effect is determined by multiple interrelated factors that may not be clearly apparent. Neural networks have been used by many engine researchers in order to develop mathematical models of dynamic engine parameters, such as smoke exhaust or boost system parameters (Brahma et al., 2004; Wu et al., 2004; Galindo et al. 2005). A study carried out by D. Willermark and $\mathrm{N}$. Smith, has trained a neural network based mathematical model that did not require large calculation resources for the modelling of Volvo engine operations during transient modes (Willermark, Smith 2009). It has also been applied to investigate turbocharger operation during transient loads (Winkler 2008). Deng et al. have used neural networks to investigate operation of the DE CAT C66 boost system. In that study, neural networks have been trained with experimental data. The modelling results obtained 
from the trained neural networks have had a correlation factor of 0.9925 with the experimental data, and correlation factors of 0.9995- 0.9999 have also been obtained for the analysis of exhaust gas emissions (Deng et al. 2011).

A combination of traditional numerical modelling tools and ANN has been used for transient mode research by K. Nikzadfar and A. H. Shamekhi. Their research has utilized the AVL BOOST internal combustion engine operation digital modelling software. To create a universal mathematical model with high calculation speeds, neural networks have been used to define changes in engine parameters and develop a mathematical model of harmful emission formation (Nikzadfar, Shamekhi 2014).

Overall, most research subjects, particularly in transient operation mode, are car engines with 2-4 cylinders and models that are primarily focused on fuel combustion parameters.

Therefore, there is a lack of research to simulate heavy DE transient performance. This study presents a DE transient operation modelling methodology that does not require the use of detailed engine parameters and provides suitable accuracy for transient operation modes. The developed methodology can be used by researchers and rail operation companies for the operation optimisation and adaptation to concrete operation conditions. Mathematical modelling results have been obtained for a locomotive series CAT3512B-HD DE during transient operation modes. Mathematical modelling with the BOOST AVL software package for a steady-state model of the CAT3512B-HD engine has been carried out in a previous study (Lebedevas et al. 2015). This model has been applied parallel with an ANN tool in this study, and this has become the basis for the determination and analysis of energy efficiency parameters in transient modes. The structure of this paper has no traditional "Methodology" chapter, as the methodology of mathematical modelling research is an objective of the research itself. The measurement of locomotive DE experimental energy parameters and processing algorithms have been described in detail in previous publications (Rapalis, Lebedeva 2014; Lebedevas et al. 2015; Rapalis et al. 2016).

\section{Methodology and Results}

\subsection{Selection and Adaptation of Transient Load Mathematical Modelling}

A primary advantage of using artificial neural networks in this study is the possibility to use data collected during trips. The ANN multi-layer perceptron method has been used for data processing. This is one of the most popular ANNs, and it is able to solve both simple and complex tasks. The multi-layer network structure consists of layers connected in series, where the inputs of each layer of neuron outputs are linked to the neurons in the previous layer, and the outputs are linked to the neurons of the next layer. Depending on the network complexity, signals are summed multiple times and transformed nonlinearly until complex concepts have been obtained using the information given by the ANN source data to generate decisions for further neural network work (Studenikin 2005; Rawlins 2005; Kriesel 2005; Graupe 2007; Nielsen 2016).

The development of an artificial neural network begins with the selection of a neural network, source data preparation, and training of the network. The neural network in this study has employed four main parameters reflecting the engine system status, as well as parameters which are not directly measured (Fig. 1).

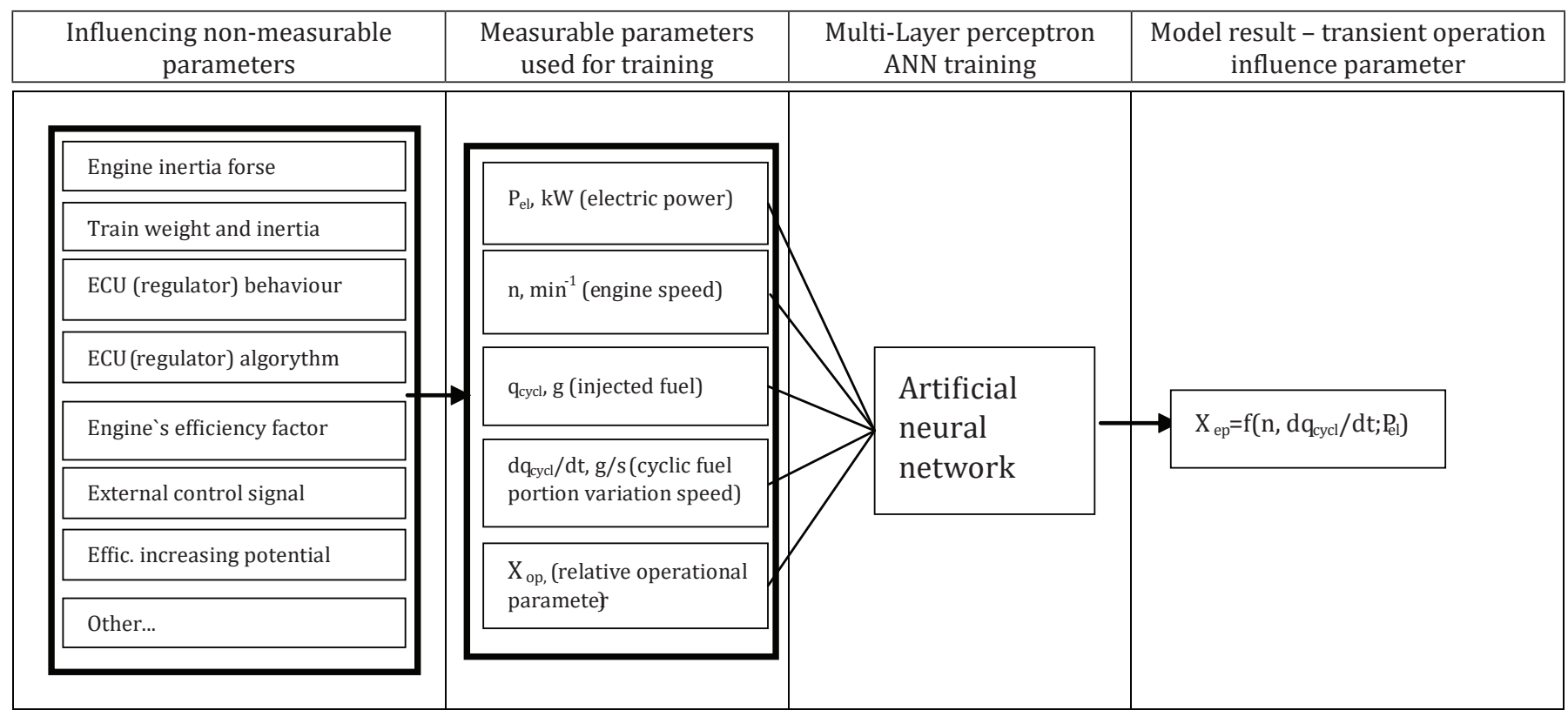

Fig. 1 General Diagram of Neural Network Based Mathematical Modelling with Unsteady Load Parameters 
To allow for practical application of the research results, both in the development of operational load cycle structures for vehicles and in the adaptation of engine control unit (ECU), parameter settings for certain DE operation conditions, a comparative analysis and generalization have been conducted for the experimental research data. This analysis has been performed by determining the relationship between the CAT3512B-HD DE operational fuel consumption and dynamic factors of the transient operational modes as follows: $\mathrm{Gf}=\mathrm{f}\left(\mathrm{q}_{\text {cycl }}\left(\mathrm{dq}_{\text {cycl }} / \mathrm{dt}\right)\right)$.

Five parameters have been selected: the first three parameters are intended to describe the engine state at a given time, while the cyclic portion variation speed is intended to estimate the engine state steadiness at a given time, and $x_{\text {op }}$ is intended to evaluate the deviation of a studied parameter from the steady state value (steady state values have been obtained as described in an earlier work (Lebedevas et al. 2015)).

- $\mathrm{P}_{\mathrm{el}}(\mathrm{kW})$ - electric power

- $\mathrm{n}\left(\mathrm{min}^{-1}\right)$ - engine revolution speed

- $\mathrm{q}_{\text {cycl }}-$ cyclic fuel portion

- $\mathrm{dq}_{\mathrm{cycl}} / \mathrm{dt}$ - cyclic fuel portion variation speed

- Xop - studied relative operational parameter
A regression function has been selected for the model, and data from several trips with the best correlation to the rheostat test data have been selected for network training. The neural network have been trained with engine operation data from a $24 \mathrm{~h}$ period, during which trip data have been recorded every $5.5 \mathrm{~s}$. The minimum and maximum number of hidden layers ( 3 and 10, respectively) have been set for the automated artificial network selection algorithm (Statistica ANN). Data intended for training have constituted $80 \%$ of the array volume, while the remaining $20 \%$ have been used for checking the results. ANN results for the relative fuel consumption, $\mathrm{x}_{\mathrm{G},}$ and electric power, $\mathrm{x}_{\mathrm{Pel}}$, during transient loads are shown in Figs. 2 and 3, respectively.

A comparison of the results obtained with the neural network and the data collected during operation has shown a high concordance rate (determination factor $R^{2}$ $\in[0.90 ; 0.99])$. These have results demonstrated the acceptable accuracy of the method for investigating fuel consumption parameters, and, with some discrepancies, for turbocharge parameters. Considering these results, it can be concluded that the training of the neural network has been successful, and the developed network is capable of
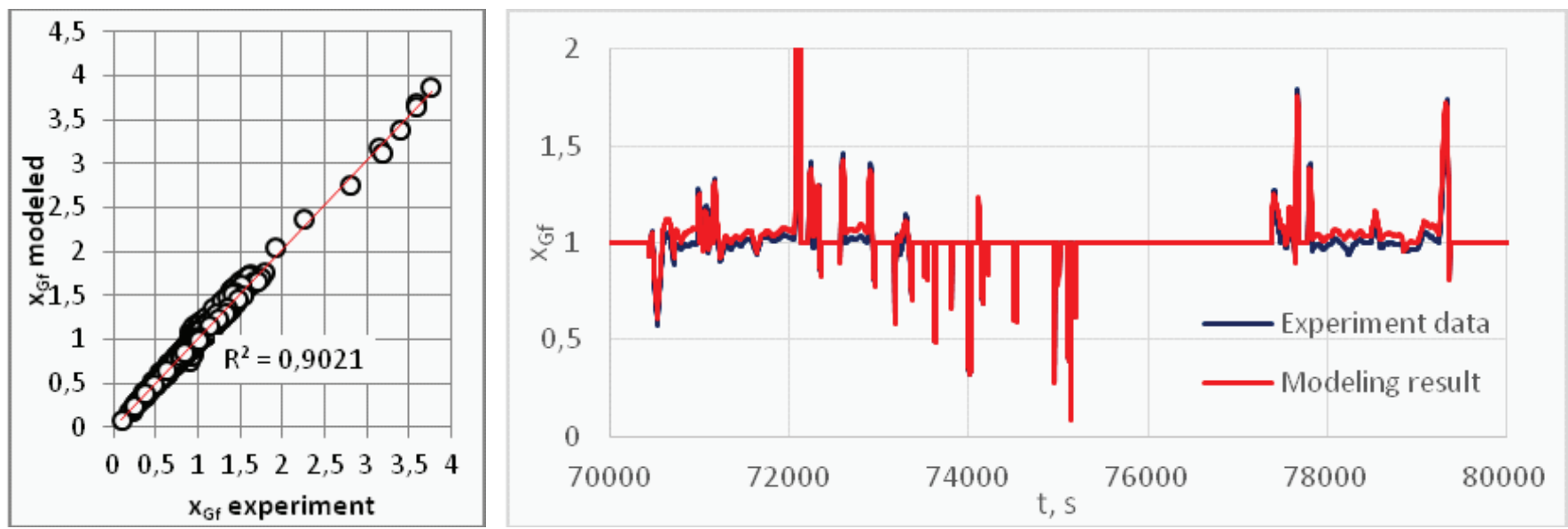

Fig. 2 Comparison of ANN Model and Experimental Results for Relative Fuel consumption, $\mathrm{x}_{\mathrm{Gf}}$
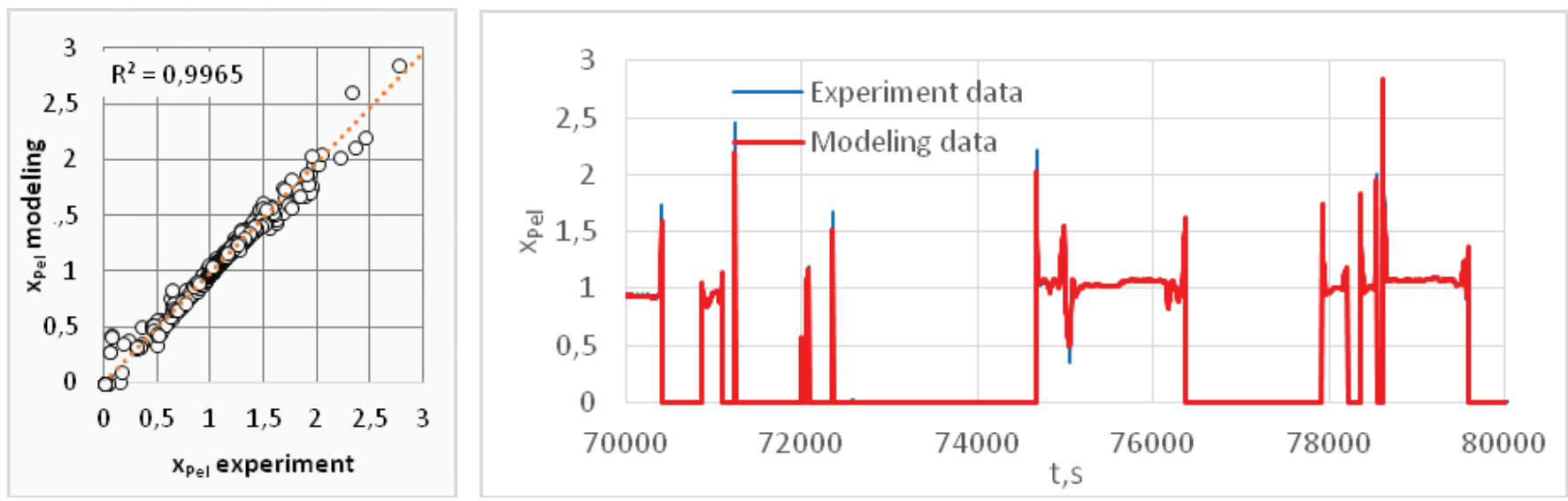

Fig. 3 Comparison of ANN Model and Experimental Results for Electric Power, $\mathrm{x}_{\mathrm{Pel}}$ 
a)

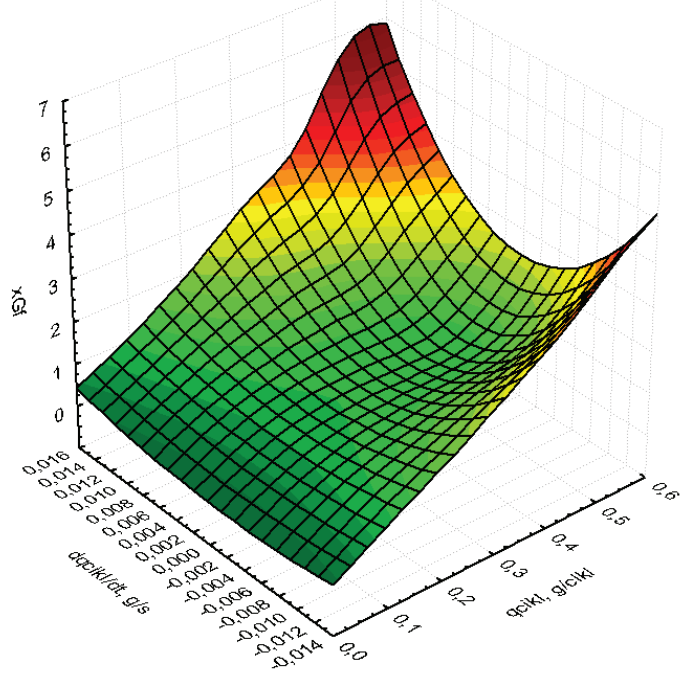

b)

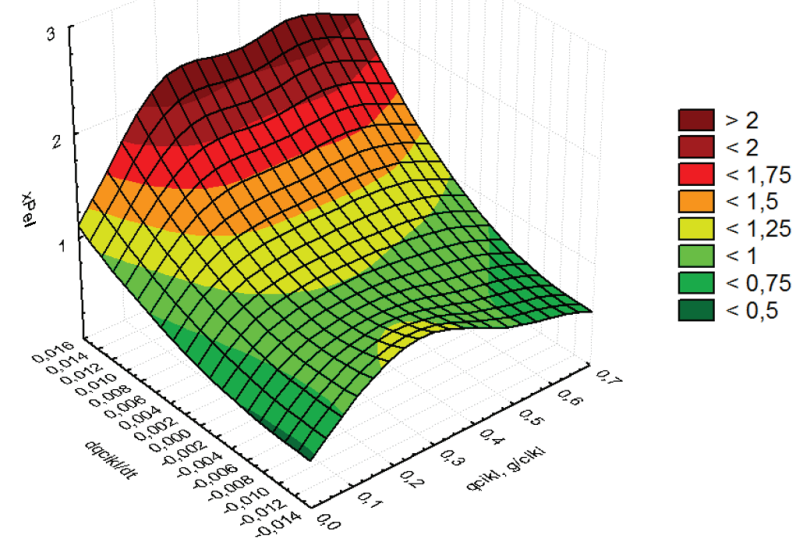

Fig. 4 Relationship between $\mathrm{x}_{\mathrm{Pel}}$ and $\mathrm{x}_{\mathrm{Gf}}$ versus $\mathrm{q}_{\mathrm{cycl}}$ and $\mathrm{dq}_{\mathrm{cyc}} / \mathrm{dt}$

modelling values of $\mathrm{x}_{\mathrm{op}}$ in the entire range of engine loads and speeds, including transient load modes. Figure $4 \mathrm{a}$ and $4 \mathrm{~b}\left(\mathrm{x}_{\mathrm{Gf}}\right.$ and $\left.\mathrm{x}_{\mathrm{Pel}}\right)$ shows a generalized relationship between the impact factors and $\mathrm{q}_{\text {cycl }}$ and $\mathrm{dq}_{\text {cycl }} / \mathrm{dt}$ (ignoring variations in the engine load and speed).

These results have shown a negative impact of increasing engine dynamics on the energy parameters. As the values get farther from $\mathrm{dq}_{\text {cycl }} / \mathrm{dt}=0$, the values of $\mathrm{x}_{\mathrm{Gf}}$ and $\mathrm{x}_{\mathrm{Pe}}$ deviate from their steady operational mode values. This is particularly easy to observe in the $\mathrm{x}_{\mathrm{Gf}}$ results in Fig. $4 \mathrm{a}$, where the cyclic portion increasing or decreasing in speed causes a significant increase in the hourly fuel consumption. At a cyclic fuel injection portion $\mathrm{q}_{\text {cycl }}=0.2 \mathrm{~g} / \mathrm{cycl}$, the cyclic portion variation of $-0.016 \mathrm{~g} / \mathrm{s}$ to $0.016 \mathrm{~g} / \mathrm{s}$ varies in the range of $<1$ to $<2$. However, when the initial cyclic portion increases to $0.5 \mathrm{~g} / \mathrm{cycl}$, while $\mathrm{dq}_{\text {cycle }} / \mathrm{dt}$ increases to $0.006 \mathrm{~g} / \mathrm{s}$ or decreases to $-0.006 \mathrm{~g} / \mathrm{s}$, the value of $\mathrm{x}_{\mathrm{Gf}}$ increases to values exceeding 2 starts, which indicates a more than doubled fuel consumption. This increase is higher for higher fuel portions. It should be noted, however, that these figures do not reflect the impact of the other two parameters, $\mathrm{P}_{\mathrm{el}}$ and $\mathrm{n}$.

\subsection{Use of ANN-supplemented BOOST AVL Model}

As discussed above, the BOOST internal combustion engine mathematical modelling software is capable of modelling both steady and transient load modes. However, the data scope required to prepare a transient load model will often exceed that available to engine fleet operators or researchers. Moreover, the model complexity will unavoidably also lead to long calculation durations. An alternative method could be the creation of a supplemental model (Fig. 5).

The BOOST software structure provides the capability to include additional user models using MATLAB-DLL files created in the Matlab Simulink environment. The creation of a MATLAB add-on and its inclusion in a BOOST model is not included in the scope of the current work (add-on creation and its inclusion in BOOST software has been planned for a future research). However, the theoretical basis for an additional model development has been established and the results obtained by recalculating the BOOST software modelling results using the same method, as shown in Fig. 5.

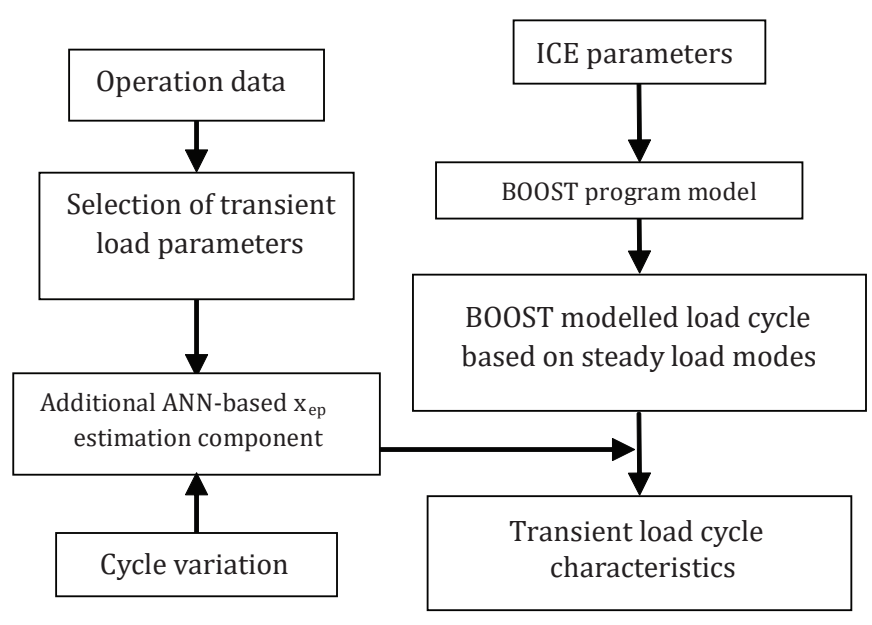

Fig. 5 Structure of the BOOST Model Supplementation Scheme

One very important aspect should be noted. Taking into account the wide applicability of artificial neural networks, such a scheme could be extended to other parameters, not in the scope of this study, such as generation of harmful emissions in a cylinder or correction of heat release models for better reflection of unsteady load modes, which has also been confirmed by scientists (Willermark, N. Smith, Winkler 2008, etc.). Figure 6 shows data modelling fragments using various algorithms. Operation values of the experimental points selected for the tests are presented in Table 1 . These points are characterised by the cyclic portion and rotation speed, and are set for the CAT3512B-HD engine model developed in the BOOST software.

The BOOST software model has estimated two of the studied operation parameters $\left(\mathrm{P}_{\mathrm{el}}, \mathrm{G}_{\mathrm{f}}\right)$ based on the steady 
Table 1 Basic Data of the BOOST and ANN Models

\begin{tabular}{|c|c|c|c|c|}
\hline $\mathbf{d q}_{\mathrm{cycl}} / \mathbf{d t} \mathbf{( g / c y c l )}$ & $\mathbf{q}_{\mathrm{cycl}} \mathbf{( g / \mathbf { c y c l } )}$ & $\mathbf{G}_{\mathbf{f}}(\mathbf{k g} / \mathbf{h})$ & $\mathbf{n}\left(\mathbf{m i n}^{-1}\right)$ & $\mathbf{P}_{\mathrm{el}} \mathbf{( k W )}$ \\
\hline-0.000987 & 0.510 & 165 & 900 & 103 \\
\hline-0.00967 & 0.456 & 145 & 884 & 89 \\
\hline-0.01039 & 0.399 & 125 & 870 & 73 \\
\hline-0.01063 & 0.340 & 105 & 857 & 59 \\
\hline-0.01086 & 0.280 & 85 & 841 & 46 \\
\hline-0.01143 & 0.217 & 65 & 827 & 32 \\
\hline
\end{tabular}

load calculation model. A part of the results has been presented in Fig. 6. As the calculation has been performed by ignoring the impact of dynamic parameters, the BOOST software model results with high error correlate with the experiments. The source data array for the ANN mathematical model trained with real operation data includes the BOOST software model results $\left(\mathrm{P}_{\mathrm{el}}\right.$ and $\mathrm{G}_{\mathrm{f}}$ values $)$ and data obtained from the experiments $\left(\mathrm{q}_{\text {cycl }}\right.$ and $\left.\mathrm{dq}_{\text {cyc }} / \mathrm{dt}\right)$. Based on the cycle dynamics parameters and BOOST model results, the ANN estimates the relative transient mode impact evaluation factors: $\mathrm{x}_{\mathrm{GP}}, \mathrm{x}_{\mathrm{Pel}}, \mathrm{P}_{\mathrm{el}}$, and $\mathrm{G}_{\mathrm{f}}$; the values obtained for these factors are close to the experimental data.

DE parameter modelling in the nominal and medium power ranges is adequate for practical application. The model has to be adjusted for application to low power range operation, although adequate mathematical models of such modes are consistent with locomotives.

It is clear that the uncorrected BOOST model without detailed data, as discussed in Sections 1 and 2, is not suitable for modelling transient modes with regard to all given parameters. The BOOST calculation results obtained by introducing an ANN-based model are much closer (for $\mathrm{P}_{\mathrm{el}}$ and $G_{r}$ the coincidence is very close, both to the absolute and relative values, as shown in Fig. 6; the errors increase only when the mode is close to idle and the BOOST model errors increase).

On the whole, these results have shown the evidence of effectiveness with the introduction of necessary additional factors associated with the combined use of a one zone of a mathematical model and ANN. To achieve adequate prac- tical application and accuracy, ANN parameters must be carefully selected according to the ICE ongoing processes.

\section{Conclusions}

The DE transient operation energy parameters for service mode identification and testing method have been developed by uniting a one zone mathematical model realized in the AVL BOOST programme and an approximation of DE electronic control system recorded parameters with a multilayer perceptron artificial neural network (ANN). The adaptation of the method for operating locomotive CAT3512B DV-HD series engines has confirmed its effectiveness; the error between mathematically modelled parameters and recorded values has been 3-4\%. In addition, the main influencing transient dynamic factors have been identified: the fuel injection cyclic portion, $\mathrm{q}_{\mathrm{cycl}}$ and its variation speed, $\mathrm{dq}_{\mathrm{cyc}} / \mathrm{dt}$.

ECU rational dynamic parameters have been examined. For example, it has been found that DE medium and lowload ranges of up to $36 \%$ of the nominal $\mathrm{q}_{\text {cycl }}$ have had a fuel overconsumption range of up to $10 \%$ compared to the corresponding steady state value, and it has had little relevance to $\left(\mathrm{dq}_{\mathrm{cyc}} / \mathrm{dt}\right), \mathrm{q}_{\mathrm{cycl}}$ nom, or the $\mathrm{q}_{\text {cycl }}$ range $(36 \%$ to $100 \%$ of $\mathrm{q}_{\text {cycl }}$ nom). To avoid an overuse of $100 \%$ or greater, it is necessary to limit the $\mathrm{dq}_{\text {cycl }} / \mathrm{dt}$ range $(-0.006$ $\left.\mathrm{g} / \mathrm{s}<\left(\mathrm{dq}_{\text {cycl }} / \mathrm{dt}\right)<+0.006 \mathrm{~g} / \mathrm{s}\right)$. The techniques developed in this study are effective for optimising vehicle operating cycle structure, a nd replicating the operating conditions and characteristics of transport infrastructure.
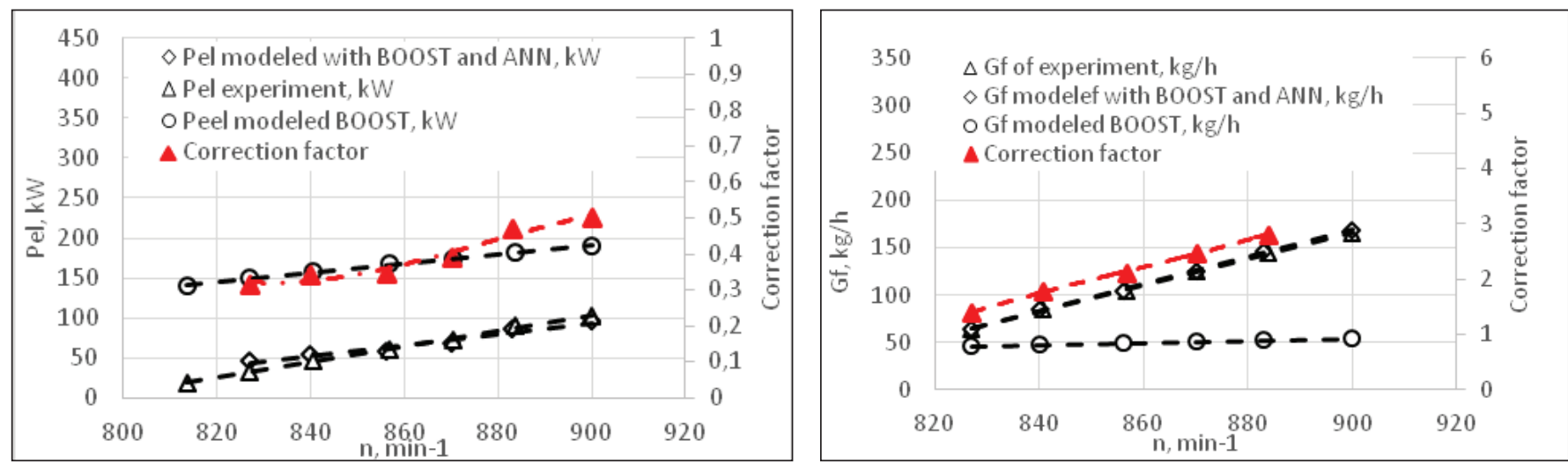

Fig. 6 Engine Power (a), and Fuel Consumption (b), Calculated by Using the BOOST Model without an Add-on, BOOST Model with an add-on, and Measured during Actual Operation 


\section{Acknowledgements}

The research results described in this paper have been obtained by using the virtual internal engine simulation tool AVL BOOST, acquired by signing the Cooperation Agreement between AVL Advanced Simulation Technologies and the Faculty of Transport Engineering of Vilnius Gediminas Technical University.

The authors have expressed a gratitude to SC „Lietuvos geležinkeliai" for providing the opportunity to cooperate and have access to their infrastructure and data that have been necessary for the research. We hope to continue our cooperation in the future.

\section{References}

[1] Assanis D. N. 1985. A Computer Simulation of the Turbocharged Turbocompounded Diesel Engine System for Studies of Low Heat Rejection Engine Performance. Ph.D. Thesis. M.I.T.

[2] Bermúdez, V.; Piqueras, P.; Garcia Afonso, O.; Serrano Cruz, J. R. 2011. Assessment by means of gas dynamic modelling of a pre-turbo diesel particulate filter configuration in a turbocharged HSDI diesel engine under full-load transient operation. Proceedings of the institution of mechanical engineers part d-journal 225(9):1134-1155.

[3] Brahma A., Upadhyay D., Serrani A., Rizzoni G. Modeling, 2005 identification and state estimation of diesel engine torque and NOx dynamics in response to fuel quantity and timing excitations IEEE Xplore: 24.

[4] Brand C. Beyond 2016 'Dieselgate': Implications of unaccounted and future air pollutant emissions and energy use for cars in the United Kingdom Energy Policy Volume 97, pp. 1-12.

[5] Brzozowska L., Brzozowski K.; Nowakowski J. 2007 An Application of Artificial Neural Network to Diesel Engine Modelling, , IEEE, Print ISBN: 0-7803-9445-3, DOI: 10.1109/ IDAACS.2005.282958

[6] Chakrabarti A., Kastha D., Mohan B. M., Das B., Kasari P.R. 2012 Nonlinear Transient Modeling of a Diesel Engine. Proc. of Int. Conf. on Advances in Power Electronics and Control System, Full Paper.

[7] Deng J.; Stobart R.; and Maass B. 2011 The Applications of Artificial Neural Networks to Engines. InTechOpen 15.

[8] Florián M., Macek J., Polášek M., Steinbauer P., Šika Z., Takats M., Vaculín O., Valášek M., Vávra J., Vítek O., Doleček V. 2006. Improving the Engine Transient Performance using Modelbased Predictive Control. THIESEL Conference on Thermo - and Fluid Dynamic Processes in Diesel Engines.

[9] Galindo J., Lujan M. J., Serrano R. J., Dolz V., Guilain S. 2004. Design of an exhaust manifold to improve transient performance of a high-speed turbocharged diesel engine. Experimental Thermal and Fluid Science 28:863-875.

[10] Graupe D. Principles of artificial neural networks (2nd Edition). Advanced Series on Circuits and Systems - Vol. 6 World Scientific Publishing Co. Pte. Ltd. 5 Toh Tuck Link, Singapore 596224.

[11] Günter P. Merker, Ing. Christian Schwarz, Dr.-Ing. habil Gunnar Stiesch, Dr. rer. nat. Frank Otto Simulating Combustion isbn 10 3-540-25161-8 Berlin Heidelberg New York.
[12] Gürgen S., Ünver B,. Altın I. 2018 Prediction of cyclic variability in a diesel engine fueled with n-butanol and diesel fuel blends using artificial neural network Renewable Energy Vol. 117, pp. 538-544.

[13] Imamori Y., Hiraoka K., Endo H., Oda Y. 2011. Combustion Simulations Contributing to the Development of Reliable Low-Emission Diesel Engines. Mitsubishi Heavy Industries Technical Review 48(1).

[14] Ismaila H. M., Nga H. K., Quecka C. W., Ganb S. 2012 Artificial neural networks modelling of engine-out responses for a light-duty diesel engine fuelled with biodiesel blends Applied Energy Vol. 92, pp. 769-777.

[15] Kotus M.; Pexa M.; Kubin K. 2013. Modelling of Non-Road Transient Cycle - Comparison of Three Tractors. Journal of Central European Agriculture 14(4):1281-1294.

[16] Kriesel D. A. 2005Brief Introduction to Neural Networks (dkriesel.com) available online http://www.dkriesel.com/_ media/science/neuronalenetze-en-zeta2-2col-dkrieselcom. pdf

[17] Kshirsagar C. M., Anand R. 2017 Artificial neural network applied forecast on a parametric study of Calophyllum inophyllum methyl ester-diesel engine out responses Applied Energy Vol. 189, pp. 555-567.

[18] Kumar S., Chauhan M. K., Varun, 2013 Numerical modeling of compression ignition engine: A review. Renewable and Sustainable Energy Reviews Vol. 19, pp. 517-530.

[19] Kurtgoz Y. Karagoz M. Deniz E. 2018 Biogas engine performance estimation using ANN Engineering Science and Technology, an International Journal Available online 5, In Press, Corrected Proof.

[20] Lebedevas S., Dailydka S., Jastremskas V., Rapalis P. 2015 The influence of locomotive diesel engine transient operating modes on energy usage Transportation Research Part D: Transport and Environment Vol. 34, pp. 219-229.

[21] Manieniyana V., Vinodhinib G. , Senthilkumarc R. , Sivaprakasamc S. 2016 Wear element analysis using neural networks of a DI diesel engine using biodiesel with exhaust gas recirculation Energy Volume 114, 1 November, pp. 603-612.

[22] Nielsen M. 2016. Neural Networks and Deep Learning. http://neuralnetworksand deeplearning.com/chap1.html

[23] Nikzadfar K., Shamekhi A H. 2014. Investigating the relative contribution of operational parameters on performance and emissions of a common-rail diesel engine using neural network Fuel Vol. 125, pp. 116-128.

[24] Nüescha T.; Wanga M.; Isenegger P.; Onder C. H.; Steiner R.; Macri-Lassus P.; Guzzellaa L. 2014. Optimal energy management for a diesel hybrid electric vehicle considering transient PM and quasi-static NOx emissions. Control Engineering Practice 29: 266-276.

[25] Rakopoulos C. D., Giakoumis E. G. 2006. Sensitivity analysis of transient diesel engine simulation. Automobile Engineering 220: 89-101.

[26] Rakopoulos C. D.; Giakoumis E. G.; Hountalas D. T. 1998. Experimental and simulation analysis of the transient operation of a turbocharged multi - cylinder idi diesel engine. International jounal of energy research 22: 317-331.

[27] Rakopoulos C.D.; Giakoumis E. G. 2009. Diesel Engine Transient Operation Principles of Operation and Simulation Analysis. Springer 390.

[28] Rakopoulos C.D.; Giakoumis E.G. 2004. Availability analysis of a turbocharged diesel engine operating under transient load conditions. Energy 29:1085-1104. 
[29] Rakopoulos C.D.; Giakoumis E.G. 2006. Review of Thermodynamic Diesel Engine Simulations under Transient Operating Conditions. SEA International Journal of Engines 2006-01-0884.

[30] Rakopoulos C.D.; Giakoumis E.G.; Hountalas D.T. 1998. Experimental and Simulation Analysis of the Transient Operation of a Turbocharged, MultiCylinder IDI Diesel Engine. Energy Research 21:317-332.

[31] Rakopoulos, C.D.; Giakoumis E.G. 1998. Simulation and Analysis of a Naturally Aspirated, Indirect Injection Diesel Engine under Transient Conditions Comprising the Effect of Various Dynamic and Thermodynamic Parameters. Energy Conversion and Management 39:465-484.

[32] Rapalis P. Lebedeva G., Gudaitytè I. 2013 Comparative analysis of diesel engine mathematical modelling packages for practical use on transport diesel engine operating on biodiesel // Transbaltica 2013. Proceedings of the 8th International Scientific Conference. May 9-10, Vilnius Gediminas Technical University; pp. 173-178, ISSN 2029-2376 (print), ISSN 2029-2384 (online).

[33] Rapalis P., Lebedeva G. Sunkiojo transporto variklio eksploatacinių rodiklių matematinio modeliavimo tyrimai // Mobile Machines 2014. International Scientific Conference Proceedings. - 2014 September 25-26, Kaunas, ASU; p. 24-29, ISBN 978-609-449-067-5.

[34] Rapalis P., Lebedeva G. Transporto paskirties dyzelinio variklio pereinamųų režimų tyrimas eksploatacijos sąlygomis // Technologijos mokslo darbai Vakarą Lietuvoje IX. - 2014, Klaipèda: KU 1-kla; pp. 155-158, ISSN 1822-4652.

[35] Rapalis Paulius, Lebedeva Galina, Lebedevas Sergejus, Heavy Transport Diesel Engine Operational Energy Parameter Mathematical Modelling Research Procedia Engineering Volume 134, 2016, pp. 371-376.

[36] Rawlins Sreve Mark. Diesel engine performance modelling using neural networks. Dissertation. Faculty of Engineering, Science and the Built Environment, Department of Mechanical Engineering, Durban, Kwazulu Natal, South Africa, June, 2005.

[37] Roy S., Banerjee R., Bose P. K. Performance and exhaust emissions prediction of a CRDI assisted single cylinder diesel engine coupled with EGR using artificial neural network. Applied Energy Volume 119, 15 April 2014, Pages 330-340.

[38] Statistica ANN available online (http://documentation. statsoft.com/STATISTICAHelp.aspx?path=SANN /Overview/ SANNNeuralNetworksAnOverview)
[39] Studenikin 0. 2005. Atvirkštinio skleidimo neuroniniai tinklai vaizdu atpažinimas. Magistro darbas Kauno technologijos universitetas informatikos fakultetas sisteminès analizès katedra, Kaunas.

[40] Taghavifar H., Khalilarya S., Jafarmadar S. Diesel engine spray characteristics prediction with hybridized artificial neural network optimized by genetic algorithm Energy Volume 71, 15 July 2014, pp. 656-664.

[41] Tanga Y., Zhanga J., Gana H., Jiaa B., Xiab Y. Development of a real-time two-stroke marine diesel engine model with incylinder pressure prediction capability Applied Energy Volume 194, 15 May 2017, pp. 55-70.

[42] White paper European Commission. Roadmap to a single European transport area - towards competitive and resource efficient transport system. Brussels; 2011. <http:// eur-lex.europa.eu/LexUriServ/ LexUriServ.do?uri=COM:20 11:0144:FIN:EN:PDF> (accessed 02.02.16).

[43] Willermark D.; Smith N. 2009. GT-POWER Real-Time - Diesel engine model for Hardware in the Loop testing. Semcon GT-SUITE Conference.

[44] Winkler N. 2008. Transient simulations of heavy-duty diesel engines with focus on the turbine. Technical Reports from Royal Institute of Technology KTH Internal Combustion Engines SE - 10044 Stockholm, Sweden.

[45] Wu B.; Filipi Z.; Assanis D.; Kramer D. 2004. Using artificial neural networks for representing the air flow rate through a 2.4 litre VVT engine. SEA International Journal of Engines 2004-01-3054.

[46] Yelvington P. E.. 2013. Development of a New Turbocharged Diesel Engine for Military Power Generation and Vehicle Applications. Ricardo Software Conference - Detroit, MI.

[47] Yua M., Tang X., Lin Y., Wang X. Diesel engine modelling based on recurrent neural networks for a hardware-inthe-loop simulation system of diesel generator sets Neurocomputing Available online 27 December 2017 In Press, Accepted Manuscript.

[48] Zbarcea O., Scarpete D., Vrabie V. Environmental pollution by diesel engines. Part ii: a literature review regarding $\mathrm{HC}, \mathrm{CO}, \mathrm{CO}_{2}$ and soot emissions. Termotehnica Supliment $1 / 2016$.

[49] Zhang G.; Filipi Z.S.; Assanis D.N. 1997. A Flexible, Reconfigurable, Transient Multi-Cylinder Diesel Engine Simulation for System Dynamics Studies. Mechanics Based Design of Structures and Machines 25(3): 357-378. 